\title{
Mendesain Bahan Ajar Berbasis Multimedia Bagi Dosen dan Mahasiswa PGSD FKIP Universitas Djuanda Bogor
}

\author{
Ridha Sefina Samosir ${ }^{1)}$, Mira Ziveria ${ }^{2)}$, Satya Candrasari ${ }^{3)}$, Salman ${ }^{4)}$ \\ ${ }^{1,2)}$ Sistem Informasi, Institut Teknologi dan Bisnis Kalbis \\ Pulomas Selatan Kav 22 Jakarta Timur 13210 \\ ${ }^{1)}$ Email: ridha.samosir@kalbis.ac.id \\ ${ }^{2) E m a i l: m i r a . z i v e r i a @ k a l b i s . a c . i d}$ \\ ${ }^{3,4)}$ Ilmu Komunikasi, Institut Teknologi dan Bisnis Kalbis \\ Pulomas Selatan Kav 22 Jakarta Timur 13210 \\ ${ }^{3)}$ Email: satya.candrasari@kalbis.ac.id \\ 4)Email: salman.naning@kalbis.ac.id
}

\begin{abstract}
Djuanda University, which was founded in 1987, is a private university with its address at No. 1 Ciawi Toll Road, Ciawi Bogor, West Java. Pendidikan Guru Sekolah Dasar (PGSD) is one of the majors in the Fakultas Keguruan dan Ilmu Pendidikan (FKIP) Djuanda University. This community service activity is in the form of training provided by lecturers of the Information Systems Study Program and the Communication Studies Program of the Kalbis Institute of Technology and Business with the topic of Designing Multimedia-Based Teaching Materials for Lecturers and Students of PGSD FKIP University of Djuanda. This training aims to improve the expertise and skills of lecturers and students of PGSD FKIP Djuanda University in creating and developing interactive and animative teaching media using Adobe Flash which will indirectly increase students' interest in learning. The training was held on 19 and 26 January 2015 in the Micro Teaching room of FKIP Djuanda University, Bogor. The training which consists of two modules is expected to be very supportive and helpful for lecturers and students of PGSD FKIP Djuanda University to improve their ability to design multimedia-based teaching materials using Adobe Flash.
\end{abstract}

Keywords: adobe flash, multimedia, training, teaching materials

\begin{abstract}
Abstrak: Universitas Djuanda yang didirikan pada tahun 1987 merupakan salah satu perguruan tinggi swasta yang beralamat di Jalan Tol Ciawi No.1, Ciawi Bogor, Jawa Barat. Pendidikan Guru Sekolah Dasar (PGSD) merupakan salah satu jurusan pada Fakultas Keguruan dan Ilmu Pendidikan (FKIP) Universitas Djuanda. Kegiatan pengabdian kepada masyarakat ini berupa pelatihan yang diberikan oleh dosen Program Studi Sistem Informasi dan Program Studi Ilmu Komunikasi Institut Teknologi dan Bisnis Kalbis dengan topik Mendesain Bahan Ajar Berbasis Multimedia bagi Dosen dan Mahasiswa PGSD FKIP Universitas Djuanda. Pelatihan ini bertujuan untuk meningkatkan keahlian dan keterampilan dosen dan mahasiswa PGSD FKIP Universitas Djuanda dalam membuat dan mengembangkan media ajar yang interaktif dan animatif menggunakan Adobe Flash yang secara tidak lansung akan meningkatkan minat belajar peserta didik. Pelatihan dilaksanakan pada tanggal 19 dan 26 Januari 2015 di ruang Micro Teaching FKIP Universitas Djuanda Bogor. Pelatihan yang terdiri dari dua modul ini diharapkan akan sangat mendukung dan membantu dosen dan mahasiswa PGSD FKIP Universitas Djuanda untuk meningkatkan kemampuan mendesain bahan ajar berbasis multimedia menggunakan perangkat Adobe Flash.
\end{abstract}

Kata kunci: adobe flash, bahan ajar, multimedia, pelatihan

\section{PENDAHULUAN}

\section{A. Universitas Djuanda}

Universitas Djuanda (UNIDA) didirikan pada tahun 1987. UNIDA merupakan salah satu perguruan tinggi swasta yang ada di Indonesia. Alamatnya di Jalan Tol Ciawi No.1, Ciawi Bogor, Jawa Barat. Fakultas yang disediakan oleh pihak UNIDA adalah Fakultas Pertanian, Fakultas Ilmu Pangan Halal, Fakultas Ekonomi, Fakultas Ilmu Sosial dan Politik,
Fakultas Hukum, Fakultas Ekonomi Islam, Fakultas Pascasarjana, serta Fakultas Keguruan dan Ilmu Pendidikan. UNIDA termasuk dalam dinamika perguruan tinggi sehingga UNIDA masuk pada rangkaian upaya perbaikan kualitas diri dan usaha besar bersama sebangsa dalam pembentukan Sumber Daya Manusia (SDM) berkualitas. SDM yang unggul adalah yang memiliki visi jauh kedepan, matang intelektual, berkepribadian luhur dan mempunyai keterampilan kerja tinggi atau profesional. 
Fakultas Keguruan dan Ilmu Pendidikan merupakan salah satu fakultas di UNIDA yang memiliki tujuan antara lain: (1) Tersedianya panduan kegiatan pengajaran, penelitian dan pengabdian kepada masyarakat sesuai dengan paradigma tauhid; (2) Tersosialisasinya kegiatan pengajaran, penelitian dan pengabdian kepada masyarakat sesuai dengan paradigma tauhid kepada seluruh insan akademika; (3) Terealisasinya model kegiatan pengajaran, penelitian dan pengabdian kepada masyarakat sesuai dengan paradigma tauhid kepada seluruh insan akademika; dan lain sebagainya; (4) Menghasilkan inovasi IPTEKS dalam bidang keguruan dan ilmu pendidikan sesuai dengan paradigma tauhid yang diakui di tingkat nasional.

Kemajuan teknologi informasi dan komunikasi mempengaruhi banyak sektor kehidupan. Guru yang bergelut di bidang pendidikan dan pengajaran juga tidak luput dari pengaruh tersebut. Guru dituntut untuk mengikuti perkembangan teknologi, terutama sekali teknologi informasi dan komunikasi (TIK) yang berkembang sangat pesat dalam beberapa tahun terakhir. Apabila guru tidak mampu mengikuti kecepatan perubahan teknologi, maka dikhawatirkan guru akan gagal menjalankan fungsinya sebagai pengajar dan pendidik. Seiring dengan kemajuan teknologi, ada banyak sarana dan prasarana yang membuat proses belajar mengajar (PBM) jauh lebih menyenangkan bagi peserta didik. Ini mengakibatkan PBM yang mengandalkan kapur dan papan tulis nampaknya akan semakin ditinggalkan tergilas oleh kemajuan teknologi.

Guru dalam kegiatan pengajarannya dapat memanfaatkan laptop dan LCD proyektor dalam memberi materi pelajaran kepada para siswanya. Melalui kecanggihan teknologi ini PBM pastinya akan menjadi jauh lebih menarik. Dan, semakin kreatif guru dalam memanfaatkan teknologi, maka akan semakin baik pula daya serap siswa terhadap materi pelajaran.

Tidak dapat kita pungkiri bahwa masih banyak guru yang masih gagap teknologi (gaptek). Contoh sederhananya adalah dalam hal pengoperasian komputer. Tidak sedikit guru yang tidak dapat mengoperasikan komputer. Padahal kemampuan mengoperasikan komputer adalah langkah awal dalam memanfaatkan kemajuan teknologi lainnya. Jadi dapat dikatakan bahwa guru belum secara optimal memanfaatkan kemajuan teknologi dalam fungsinya sebagai tenaga pengajar dan pendidik.

Dari sebagian latar belakang tersebut
flash merupakan salah satu jawabannya.
Dengan flash para guru bisa meningkatkan motivasi belajar siswa, dengan menggunakan media tentunya. dan media tersebut dibuat dengan menggunakan flash. Mungkin bagi sebagian orang yang belum pernah mempelajari flash, flash merupakan program yang sulit dipelajari. itu merupakan hal yang sangat salah sekali. flash sangat cocok sekali bila digunakan untuk membuat media ajar yang interaktif dan animatif dari segi tampilan dan juga mengena dalam segi tujuan karena dengan adanya media yang menarik akan membuat minat belajar siswa menjadi meningkat.

Sehubungan dengan hal tersebut di atas dan dalam rangka mewujudkan salah satu Tri Dharma Perguruan Tinggi yaitu pengabdian kepada masyarakat, program studi Sistem Informasi akan mengusulkan program "Mendesain Bahan Ajar Berbasis Multimedia bagi Dosen dan Mahasiswa PGSD - FKIP Universitas Djuanda Bogor" bulan Januari 2015 di laboratorium komputer FKIP UNIDA Bogor - Jawa Barat.

Universitas Djuanda didirikan berdasarkan Surat Keputusan Badan Pengurus Yayasan PSPI Nomor: 83/YPSPI/III/87 tanggal 21 Maret 1987. Gagasan untuk mendirikan Lembaga Pendidikan Tinggi dalam bentuk Universitas yang kemudian bernama Universitas Djuanda (UNIDA).

Visi Universitas Djuanda adalah menjadi Universitasberkualitasuntukmencerdaskankehidupan Bangsa yang menyatu dalam Tauhid. Misi Universitas Djuanda adalah: (1) Menyelenggarakan pendidikan tinggi dengan manajemen yang bersih, transparan dan profesional sejalan dengan prinsip Good University Governance (GUG) dalam kehidupan kampus yang Bertauhid, (2) Mengajarkan, mengembangkan dan mengamalkan ilmu pengetahuan dan teknologi serta meningkatkan iman dan taqwa untuk kesejahteraan dan kemakmuran bangsa, dan (3) Menghasilkan lulusan yang cerdas intelektual, emosional, spiritual dan memiliki kompetisi dibidangnya serta berjiwa kewirausahaan/Entrepreunership. Tujuan Universitas Djuanda adalah: (1) Terselenggaranya pendidikan dan pengajkar yang modern, berkualitas dan bertauhid, (2) Mengembangkan dan memberdayakan sumberdaya manusia sesuai dengan paradigma Tauhid, (3) Terlaksanannya penelitian dan pengabdian pada masyarakat yang berkelanjutan baik kualitan maupun kuantitas, (4) Terselenggaranya proses belajar mengajar berdasarkan kurikulum yang tersusun secara terintegritas (link and match), (5) Mengevaluasi dan mengembangkan kurikulum sesuai dengan kebutuhan, (6) Terbentuknya jaringan kerjasama denga berbagai pihak yang saling menguntugkan, (7) 
Terselenggaranya pelayanan kependidikan berkualias yang memenuhi kepuasan (satisfication) pemangku kepentingan (stakeholder), (8) Terciptanya lulusan yang berkualitas, berdaya guna, berhasil guna, kreatif inovatif dan mandiri, dan (9) Terciptanya hubungan yang konstruktif antara alumni dengan almamater.

\section{B. Fakultas Keguruan dan Ilmu Pendidikan Universitas Djuanda}

Universitas Djuanda mempunyai delapan fakultas, yaitu fakultas pertanian, fakultas ilmu pangan halal, fakultas Ekonomi, Fakultas Ilmu Sosial dan Politik, Fakultas Hukum, Fakultas Ekonomi Islam, Fakultas Pascasarjana, dan Fakultas Keguruan dan Ilmu Pendidikan.

Fakultas Keguruan dan Ilmu Pendidikan memiliki visi Menjadi lembaga terkemuka untuk membangun Paradigma Tauhid dalam bidang keguruan dan Ilmu Pendidikan. Misinya adalah: (1) Menyelenggarakan kegiatan pengajaran, penelitian dan pengabdian kepada masyarakat sesuai dengan paradigma tauhid, (2) Mengembangkan ilmu pengetahuan dan teknologi bidang keguruan dan ilmu pendidikan sesuai dengan paradigma tauhid, (3) Membangun kerjasama nasional dan internasional dalam rangka meningkatkan mutu lembaga pendidikan yang bertauhid.

Tujuan jangka pendek tahun 2012 sampai dengan tahun 2015 adalah: (1) Tersedianya panduan kegiatan pengajaran, penelitian dan pengabdian kepada masyarakat sesuai dengan paradigma tauhid; (2) Tersosialisanya kegiatan pengajaran, penelitian dan pengabdian kepada masyarakat sesuai dengan paradigma tauhid kepada seluruh insan akademika; (3) Terealisasinya model kegiatan pengajaran, penelitian dan pengabdian kepada masyarakat sesuai dengan paradigma tauhid kepada seluruh insan akademika; (4) Menghasilkan inovasi IPTEKS dalam bidang keguruan dan ilmu pendidikan sesuai dengan paradigma tauhid yang diakui di tingkat nasional; (5) Tersosialisasinya inovasi IPTEKS dalam bidang keguruan dan ilmu pendidikan sesuai dengan paradigma tauhid kepada stakeholders dan masyarakat; dan (6) Terjalinnya kerjasama dengan lembaga pendidikan di tingkat nasional dan internasional. Struktur organisasi Fakultas Keguruan dan Ilmu Pendidikan dapat dilihat pada Gambar 1.

Keunggulan Fakultas Keguruan dan Ilmu Pendidikan Universitas Dhuanda adalah: 90\% Program Studi Terakreditasi B (Ban-PT); Kurikulum berbasis kompetensi; Cyber Campus (pengelolaan pendidikan berbasis IT); Alumni diserap di berbagai

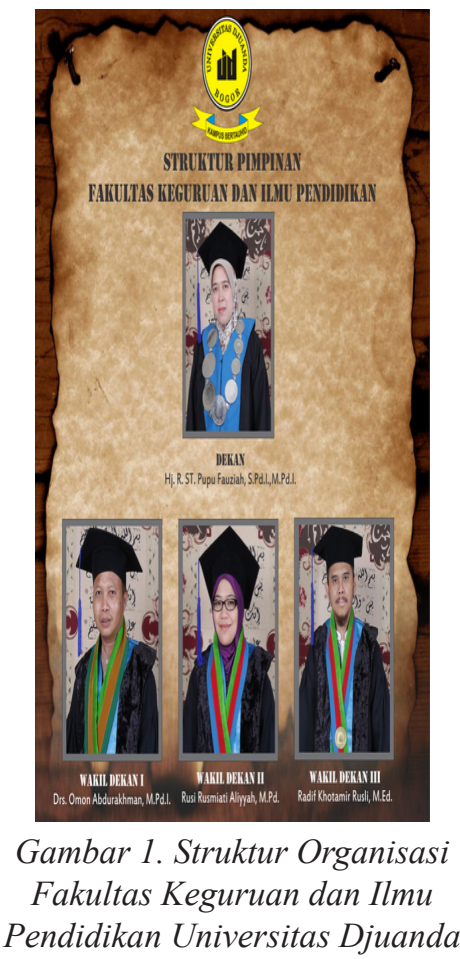

lapangan kerja, baik pemerintah maupun swasta; Biaya terjangkau; Dosen lulusan S2/S3 Universitas terkemuka, dalam dan luar negeri; Lulusan menjadi sarjana yang cerdas intelektual, emosional, spiritual, mandiri, dan kompeten; Tata kelola Universitas yang baik (Good University Government); Dibekali Vocational School; Lokasi strategis di ujung tol Ciawi, nyaman, sejuk, dan indah; dan Sarana dan prasarana yang memadai, ruang kelas nyaman, laboratorium bahasa, dan microteaching, student center, lapangan olahraga, asrama mahasiswa, sarana ibadah, poliklinik "Klinik Kampusku", Free Hostpot Area. Beberapa fasilitas yang merupakan keunggulan dari Fakultas Keguruan dan Ilmu Pendidikan dapat dilihat pada Gambar 2.
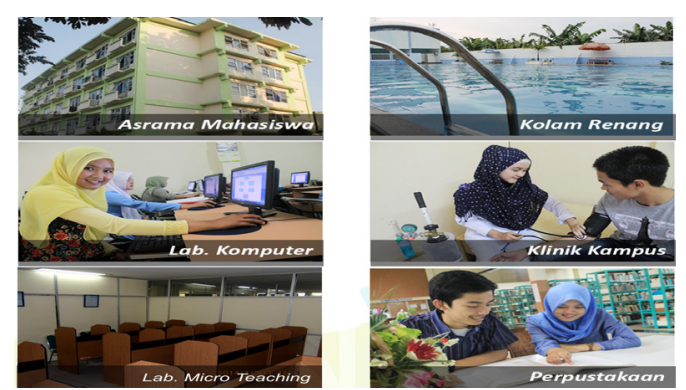

Gambar 2. Fasilitas Fakultas Keguruan dan Ilmu Pendidikan Universitas Djuanda

Untuk menunjang keahlian dosen dan mahasiswa Fakultas Keguruan dan Ilmu Pendidikan Universitas Djuanda, tentunya diperlukan keterampilan dalam mendesain bahan ajar berbasis multimedia.

Keterampilan mendesain bahan ajar berbasis multimedia diperlukan oleh dosen dan mahasiswa Fakultas Keguruan dan Ilmu Pendidikan Universitas 
Djuanda yang dapat diterapkan untuk menyajikan bahan ajar yang menarik dan interaktif, sehingga lebih mudah dipahami oleh siswa atau mahasiswa yang diajar.

Sehubungan dengan hal tersebut di atas dan dalam rangka mewujudkan salah satu Tri Dharma Perguruan Tinggi yaitu pengabdian kepada masyarakat, program studi Sistem Informasi dan Ilmu Komunikasi Kalbis Institute mengusulkan program pelatihan dengan topik "Mendesain Bahan Ajar Berbasis Multimedia bagi Dosen dan Mahasiswa PGSD-FKIP Universitas Djuanda".

\section{METODE PELAKSANAAN}

\section{A. Topik Kegiatan}

Sebagai program studi yang terkait dengan bidang teknologi dan bisnis maka Prodi Sistem Informasi dan Ilmu Komunikasi Kalbis Institute sangat antusias untuk ikut berpartisipasi dalam kegiatan PKM kerjasama antara Kalbis Institute dengan Universitas Djuanda.

Berdasarkan tujuan dari mitra sendiri yang ingin menyediakan panduan kegiatan pengajaran, penelitian dan pengabdian kepada masyarakat sesuai dengan paradigma tauhid dan menghasilkan inovasi IPTEKS dalam bidang keguruan dan ilmu pendidikan sesuai dengan paradigma tauhid yang diakui di tingkat nasional maka dengan beberapa pertimbangan para dosen pada Prodi Sistem Informasi mengusulkan untuk memberikan pelatihan "Mendesain Bahan Ajar Berbasis Multimedia bagi Dosen dan Mahasiswa PGSD - FKIP Universitas Djuanda Bogor".

\section{B. Tujuan Kegiatan}

Tujuan Kegiatan secara khusus Prodi Sistem Informasi dan Prodi Ilmu Komunikasi mengharapkan nantinya para dosen dan mahasiswa PGSD FKIP Universitas Djuanda punya pengetahuan tentang komunikasi multimedia dan keahlian secara praktikal untuk membuat media ajar yang interaktif dan animatif menggunakan Macromedia Flash. Secara Umum adalah Dari keahlian itu maka nantinya para dosen dan mahasiswa PGSD FKIP Universitas Djuanda dapat mengembangkan media pembelajaran yang lebih menarik dan menyenangkan bagi peserta didik sehingga minat belajar siswa menjadi meningkat.

\section{Manfaat Kegiatan}

Manfaat kegiatan bagi Program Studi Sistem Informasi dan Ilmu Komunikasi Kalbis Institute adalah Pemenuhan kewajiban Pengabdian Pada Masyarakat bagi Dosen, meningkatkan keahlian dosen melalui proses sharing pengetahuan dan keahlian bagi mitra, memperbanyak relasi dengan mitra untuk berbagai fungsi positif, dan memberikan pengalaman baru bagi dosen-dosen Prodi Sistem Informasi dan Prodi Ilmu Komunikasi mengenai pemanfaatan teknologi untuk mengembangkan media pengajaran lebih efektif.

Manfaat kegiatan bagi dosen dan mahasiswa PGSD FKIP Universitas Djuanda adalah Meningkatkan keahlian secara praktikal mengenai Macromedia Flash, memberikan pengenalan mengenai konsep dan perangkat pendukung Macromedia Flash, dapat mengembangkan media ajar menggunakan Macromedia Flash, dan Lebih mengenal Kalbis Institute.

\section{Metode Pendekatan}

Sesuai dengan permasalahan diatas, maka kami Dosen Program Studi Sistem Informasi Fakultas Ilmu Komputer dan Ilmu Komunikasi Kalbis Institute akan mengadakan pelatihan dengan tema "Mendesain Bahan Ajar Berbahasis Multimedia bagi Dosen dan Mahasiswa PGSD - FKIP Universitas Djuanda Bogor" bulan Januari 2015 di laboratorium komputer FKIP UNIDA Bogor - Jawa Barat.

Tema pelatihan yang ditawarkan adalah:

Bagian 1 (Komunikasi Mutimedia) yang terdiri dari:

Perangkat Multimedia

Perkembangan Multimedia

Pengaruh Multimedia

Manfaat Multimedia

Karir Multimedia

Aplikasi Multimedia

Bagian 2 (Mendesain Bahan Ajar Berbasis Multimedia) yang terdiri dari:

2.1 Pengenalan Flash

2.2 Animasi Dasar

2.3 Animasi Teks dan Image

2.4 Button

2.5 Interaktif

2.6 Presentasi

\section{E. Tinjauan Pustaka}

\section{Komunikasi Multimedia}

Istilah multimedia berawal dari teater, yaitu pertunjukan yang memanfaatkan lebih dari satu medium seringkali disebut pertunjukan multimedia. Lahirnya teknologi multimedia adalah hasil dari perpaduan kemajuan teknologi elektronik, teknik komputer dan perangkat lunak. Multimedia merupakan konsep dan teknologi dari unsur - unsur gambar, suara, animasi serta video disatukan didalam 
komputer untuk disimpan. Pemanfaatan komputer untuk membuat dan menggabungkan teks, grafik, audio, video dan animasi dengan menggabungkan link dan tool yang memungkinkan pemakai akan melakukan navigasi, berinteraksi, berkreasi dan berkomunikasi. [1]

Empat komponen penting multimedia yaitu: 1). Harus ada komputer yang mengkoordinasikan apa yang dilihat \& didengar, yang berinteraksi dengan kita; 2). Harus ada link yang menghubungkan kita dengan informasi; 3). Harus ada alat navigasi yang memandu kita, menjelajah jaringan informasi yang saling terhubung; dan 4). Multimedia menyediakan tempat kepada kita mengumpulkan, memproses dan mengkomunikasikan informasi dan ide kita sendiri.

Perangkat lunak multimedia adalah komponenkomponen dalam data processing system, berupa program-program untuk mengontrol bekerjanya system multimedia. Perangkat lunak ini digologkan menjadi tiga bagian, yaitu: bahasa pemrograman multimedia; perangkat lunak system multimedia; dan dan perangkat lunak aplikasi multimedia

Bahasa pemrograman multimedia adalah bahasa computer yang digunakan programmer untuk membuat aplikasi multimedia. Contohnya: Assembly; C, C++; Power Builder, Delphi, SQL, Visual Basic; dan Flash Programmer dan Java

Karir Multimedia antara lain: Bidang teknologi multimedia merupakan profesi baru yang sedang dibutuhkan pada saat sekarang dan yang akan datang. Imajinasi yang kuat diperlukan di bidang ini untuk dapat membayangkan, melihat potensi, menciptakan apa yang tidak terbayangkan oleh kebanyakan orang saat ini; dan Berikut ini adalah profesi yang membutuhkan teknologi multimedia : Pemasaran, animasi, desain grafis, electronic publishing, editor, desain game, public relations, spesial efek, produksi video, dan web master

Perkembangan multimedia semakin maju, hal ini disebabkan semakin beraneka ragamnya kebutuhan akan multimedia. Semakin banyaknya software yang bermunculan untuk membuat aplikasi berbasis multimedia ini. Dan juga beraneka ragam kebutuhan akan informasi. Aspek yang merupakan pendorong perkembangan multimedia diantaranya adalah hoby, telekomunikasi, consumer electronic, Televisi, movie, broadcasting industry, publishing house dll.

Manfaat multimedia antara lain: Bidang periklanan yang efektif dan interaktif; Bidang pendidikan dalam penyampaian bahan pengajaran secara interaktif dan dapat mempermudah pembelajaran karena dididukung oleh berbagai aspek: suara, video, animasi, teks, dan grafik; dan Bidang jaringan dan internet yang membantu dalam pembuatan website menarik, informatif, dan interaktif

Multimedia merupakan media interaktif yang sangat ampuh mempengaruhi manusia. Dalam hal ini multimedia mampu: Mengubah tempat kerja. Dengan adanya teleworking, para pekerja dapat melakukan pekerjaanya tidak harus dari kantor. Contoh software yang mendukung teleworking/telecommuting: Netmeeting!; Mengubah cara belanja. Homeshopping/ teleshopping dapat dilakukan dengan menggunakan internet, kemudian barang datang dengan sendirinya; Mengubah cara bisnis. Nokia membuat bisnis telepon seluler, banyak perusahaan menggunakan sistem jual beli online, bank menggunakan cara online-banking; Mengubah cara memperoleh informasi. Orang-orang mulai menggunakan internet dan berbagai software untuk mencari informasi. Misalnya: membaca koran online, detik.com, menggunakan software kesehatan, belajar gitar dari software dan masih banyak lagi; Mengubah cara belajar. Sekolah mulai menggunakan computer multimedia, belajar online, menggunakan e-boo; dan Internet Multimedia juga mulai bersaing dengan televisi dan radio.

\section{Media Pembelajaran}

Media pembelajaran dibagi menjadi 5 bentuk media pembelajaran, yaitu: [2]. Media pembelajaran dua dimensi yaitu media yang penampilannya tanpa menggunakan media proyeksi dan berukuran panjang kali lebar saja serta hanya diamati dari satu arah pandangan saja. Misalnya peta, gambar bagan dan semua jenis media yang hanya dilihat dari sisi datar saja; Media pembelajaran tiga dimensi yaitu media yang penampilannya tanpa menggunakan media proyeksi dan mempunyai ukuran panjang, lebar dan tinggi/tebal serta dapat diamati dari arah pandang mana saja. Misalnya meja, kursi, mobil, rumah dan sebagainya; Media pandang diam yaitu media yang menggunakan media proyeksi yang hanya menampilkan gambar diam di layar (tidak bergerak/ statis). Misalnya foto, tulisan, atau gambar binatang yang dapat diproyeksikan; Media pandang gerak yaitu media yang menggunakan media proyeksi yang dapat menampilkan gambar bergerak di layar, termasuk media televisi dan video tape recorder termasuk media pandang bergerak yang disajikan melalui layar (screen) di komputer atau layar lainnya; dan Media pembelajaran multimedia yaitu media pembelajaran yang menggabungkan unsur audio, visual, dan simulasi. 
Fungsi media secara umum, sebagai berikut: Memperjelas penyajian pesan agar tidak terlalu bersifat visual; Mengatasi keterbatasan ruang, waktu, dan daya indera, misal objek yang terlalu besar untuk dibawa ke kelas dapat diganti dengan gambar, slide, peristiwa yang terjadi di masa lalu bisa ditampilkan lagi lewat film, video, foto atau film bingkai.; Meningkatkan kegairahan belajar, memungkinkan siswa belajar sendiri berdasarkan minat dan kemampuannya, dan mengatasi sikap pasif siswa.; dan Memberikan rangsangan yang sama, dapat menyamakan pengalaman dan persepsi siswa terhadap isi pelajaran.

Manfaat media pembelajaran adalah: Penyampaian pelajaran menjadi lebih baku; Pembelajaran bisa lebih menarik; Pembelajaran menjadi lebih interaktif dengan diterapkannya teori belajar dan prinsip- prinsip psikologis yang diterima dalam hal partisipasi siswa, umpan balik dan pengetahuan; Lama waktu pembelajaran yang diperlukan dapat dipersingkat karena kebanyakan media hanya memerlukan waktu singkat untuk mengantarkan pesan pelajaran dalam jumlah yang cukup banyak dan kemungkinan dapat diserap oleh siswa; dan Kualitas belajar.

Model ADDIE adalah metode pengembangan dan perancangan aplikasi yang meliputi lima fase yaitu, Analisa (Analyze), Desain (Design), Pengembangan (Develop), Implementasi (Implement), dan Evaluasi (Evaluate). Pada tahap analisis, pengembang melakukan analisis tentang aplikasi atau program yang akan dikembangkan dengan cara mencari informasi yang dibutuhkan, contohnya adalah mencari spesifikasi aplikasi, materi, aturan permainan dan sebagainya. Pada tahap desain, pengembang melakukan perancangan desain menggunakan beberapa cara. Pada tahap pengembangan atau development, pengembang merealisasikan konsep yang dibuat pada tahapan desain menggunakan perangkat yang dibutuhkan, baik perangkat lunak maupun perangkat keras. Pada tahap implementasi, aplikasi atau program yang telah dikembangkan, dilakukan atau diimplementasikan kepada target yang telah ditentukan. Pada tahap terakhir yaitu evaluasi, program atau aplikasi ditinjau kembali untuk melihat apakah aplikasi sudah sesuai dengan kebutuhan atau belum. [3]

\section{Pengenalan Flash}

Animasi terdiri dari dua kategori, yaitu linear dan non linear (interaktif). Movie non linear dapat berinteraksi dengan aplikasi web yang lain melalui penekanan sebuah tombol navigasi, pengisian form dan lain-lain. Designer web membuat movie non linear dengan membuat tombol navigasi, animasi logo, animasi form dengan sinkronisasi suara. Flash movie adalah grafik dan animasi untuk situs web yang merupakan grafik vektor dengan ukuran file kecil, sehingga dapat di-loas dalam waktu singkat. Pada dasarnya animasi terdiri dari grafik vektor, tetapi dapat juga dilengkapi dengan bitmap dan suara. Flash movie dapat dijalankan dengan Flash Plater melalui browser atau pada aplikasi stand alone. Flash dapat digunakan untuk membuat animasi interaktif, dimana pengunjung dapat memasukkan data, kemudian Flash mengevaluasi dan menampilkan hasilnya. [4]

Adobe Flash atau yang dikenal pada awalnya sebagai Macromedia Flash adalah salah satu perangkat lunak komputer yang merupakan produk unggulan dari Adobe Systems. Adobe Flash ini digunakan untuk membuat gambar vektor maupun animasi gambar.

Berkas yang dihasilkan dari Adobe Flash adalah swf dan dapat diputar di penjelajah web yang telah dipasangi Adobe Flash Player. Flash merupakan salah satu program yang digunkan untuk membuat animasi yang sangat handal jika dibandingkan dengan program lain karena dalam hal ukuran file dari hasil animasinya lebih kecil. Biasanya hasil animasi Flash banyak digunakan untuk membuat sebuah web agar tampilannya menjadi lebih interaktif. Flash menggunakan bahasa pemrograman bernama Action Script, bahasa pemrograman ini muncul pertama kalinya pada Flash 5.

Adobe Flash merupakan sebuah program yang didesain khusus oleh Adobe untuk keperluan pembangunan situs web yang interaktif dan dinamis sehingga sangat cocok untuk membuat animasi dan bitmap yang sangat menarik. Flash didesain dengan kemampuan untuk membuat animasi 2 dimensi yang handal dan ringan sehingga dengan kemampua ini flash banyak digunakan untuk membangun dan memberikan efek animasi pada website, CD Interaktif dan yang lainnya. Selain digunakan untuk membangun dan memberikan efek animasi aplikasi ini juga dapat digunakan untuk membuat animasi logo, movie, game, menu interaktif, interaktif form isian, e-card, screen saver, pembuatan navigasi pada situs web, tombol animasi, banner, dan pembuatan aplikasi-aplikasi web lainnya.

Flash sekarang ini bukan hanya digunakan sebagai software saja dengan nama Adobe Flash, tetapi juga merupakan suatu teknologi animasi di web. Jadi untuk membuat animasi web dengan 
format Flash (SWF) kamu tidak harus menggunakan software Adobe Flash, namun bisa juga menggunakan software lain seperti SwishMax, , Swift 3D, Amara, Kool, Vecta 3D Moves dan lainnya.

Sejarah Flash dapat ditelusuri kembali sekitar tahun 1980-an, pada waktu itu seorang siswa SMA dengan nama Jonathan Gay menggunakan komputer Apple II yang sudah tua umurnya untuk membuat program gambar komputer. Kemudian dia mengajukan dan mengikutsertakan program yang dikenal sebagai SuperPaint dalam pameran sains disekolahnya. Setelah dia menang, program buatannya tersebut menarik perhatian bagi seorang pengembang software lokal yaitu Charlie Jackson. Pada masa itu Jackson sedang dalam proses memulai sebuah perusahaan yang dikenal sebagai Silicon Pantai Software, yang akan menghasilkan program untuk jenis komputer Macintosh.

Dengan sedikit dana yang di milikinya untuk mempekerjakan para pengembang berpengalaman, akhirnya Jackson Gay disewa untuk membantu menciptakan program-programnya. Pada musim panas 1995, SmartSketch mendapat masukan dari penggunanya agar SmartSketch dapat digunakan untuk membuat animasi. Namun FutureWave sedikit kurang percaya diri mengenai pemasarannya, karena pada waktu itu animasi hanya didistribusikan dengan VHS atau CD-ROM. Namun dia tidak menyerah, kemudian World Wide Web mulai mengembangkan sayapnya, dimana akhirnya grafik dan animasi menjadi vital. FutureWave melihat kesempatan ini sebagai peluang untuk memasarkan aplikasi yang mampu menghasilkan animasi dua dimensi.

Kemudian SmartSketch sedikit dimodifikasi menjadi SmartSketch Animator. Namun, nama SmartSketch Animator dirasakan kurang menjual, sehingga nama tersebut akhirnya diubah menjadi CelAnimator. Tetapi kemudian, karena khawatir dinilai sebagai aplikasi pembuat kartun, CelAnimator diubah menjadi FutureSplash Animator. FutureSplash animator mendekati para pengembang hanya dalam beberapa bulan dari rilis program tersebut yang begitu sukses di pasar komputer dan Microsoft. Microsoft merencanakan versi online dari MSN dan percaya bahwa nantinya FutureSplash akan memberikan kualitas grafis terhalus dan tertinggi.

Selain itu Disney Online juga menggunakan program tersebut untuk mengembangkan situs web mereka. Akhirnya pada bulan November 1996, Macromedia menawarkan untuk membeli program tersebut dan pada bulan Desember Gay menerimanya. Macromedia Kemudian membeli
FutureSplash Animator yang kemudian diubah namanya menjadi Macromedia Flash 1.0 yang pada akhirnya mempekerjakan Jonathan Gay sebagai Technology Vice President.

Fungsi adoble flash yaitu: Aplikasi ini mempunyai fungsi untuk membuat logo, banner, movie, game, membuat navigasi pada web, menu interaktif, interaktif form, screen server, e-card, daftar fungsi adobe flash player; Bisa untuk memutar vidio yang berformat; Dengan adobe flash player kita harus melakukan yahooemail, facebook, DLL; Menampilkan video streaming; Mendownload video ke youtube; dan Mengunggah foto di facebook

Pada intinya fungsi Adobe Flash untuk memutar video, gambar, maupun animasi. Kelebihan Program Aplikasi Adobe Flash: Merupakan teknologi animasi web yang paling populer saat ini sehingga banyak didukung oleh berbagai pihak; Ukuran file yang kecil dengan kualitas yang baik; Kebutuhan hardware yang tidak tinggi; Apliaksi ini dapat digunakan untuk membuat website, cd-interaktif, animasi web, animasi kartun, kartu elektronik, iklan TV, banner di web, presentasi interaksi, permainan, aplikasi web dan handphone dan lainnya; Selain itu, aplikasi ini juga dapat ditampilkan di berbagai media seperti Web, CD-ROM, VCD, DVD, Televisi, Handphone dan PDA; dan Adanya Actionscript. Dengan adanya actionscript kamu dapat membuat animasi dengan menggunakan kode sehingga dapat memperkecil ukuran file. Karena adanya actionscript ini juga Flash dapat untuk membuat game karena script dapat menyimpan variable dan nilai, melakukan perhitungan, dan lainnya. yang berguna dalam game. Selain itu, Flash adalah program berbasis vektor

Kekurangan Program Aplikasi Adobe Flash: Grafisnya kurang lengkap; Lambat login; Kurang Simpel; Menunya tidak user friendly; Perlu banyak referensi tutorial; Kurang dalam 3D. Pembuatan animasi 3D cukup sulit; Bahasanya pemrogramannya agak susah; dan Belum ada template di dalamnya.

\section{HASIL DAN PEMBAHASAN}

Deskripsi kegiatan pengabdian kepada masyarakat yaitu "Mendesain Bahan Ajar Berbasis Multimedia bagi Dosen dan Mahasiswa PGSD FKIP Universitas Djuanda" tanggal 19 - 26 Januari 2015 adalah sebagai berikut:

\section{A. Perencanaan Kegiatan PKM}

Rencana ini didiskusikan dalam rapat Tim Dosen Program Studi Sistem Informasi Fakultas Ilmu 
Komputer dan Ilmu Komunikasi Institut Teknologi dan Bisnis Kalbis (Kalbis Institute) yang tergabung kedalam Tim Pengabdian Kepada Masyarakat (PKM) pada 10 September 2014 pukul $08.00-12.00$ WIB di ruang dosen Lantai 2 Kampus Kalbis Institute Jalan Pulomas Selatan Kav.22 Jakarta Timur. Diskusi ini untuk membicarakan PKM yang merupakan salah satu wujud Tri Dharma Perguruan Tinggi. Hasilnya adalah kesepakatan untuk melakukan PKM dengan mitra Universitas Djuanda Bogor Jawa Barat.

\section{B. Koordinasi Penentuan Program dan Tema PKM}

Dalam rapat Tim PKM pada 17 September 2014 pukul 10.00 - 11.30 WIB di ruang dosen Lantai 2 Kampus Institut Teknologi dan Bisnis Kalbis (Kalbis Institute) Jalan Pulomas Selatan Kav.22 Jakarta Timur dibicarakan program dan tema PKM yang diberikan bagi dosen dan mahasiswa PGSD FKIP Universitas Djuanda. Hasilnya adalah kesepakatan untuk mengadakan PKM dengan tema "Mendesain Bahan Ajar Berbasis Multimedia bagi Dosen dan Mahasiswa PGSD - FKIP Universitas Djuanda Bogor" pada bulan Januari 2015 yang bertempat di kampus PGSD FKIP Universitas Djuanda.

\section{Observasi Awal Tim PKM}

Observasi awal ke Universitas Djuanda Bogor Jawa Barat dilaksanakan tanggal 9 Oktober 2014 pukul 09.30 - 17.00 WIB. Kegiatan ini dilaksanakan di ruang Micro Teaching PGSD - FKIP UNIDA dan bertujuan untuk: Perkenalan kegiatan PKM Prodi Sistem Informasi dan Prodi Ilmu Komunikasi yang tergabung dalam tim PKM kepada mitra; Pengenalan profil PGSD FKIP Universitas Djuanda; Pemberian saran-saran dari para pendidik PGSD FKIP Universitas Djuanda agar kegiatan pengabdian masyarakat tepat sasaran dan bermanfaat bagi para dosen dan mahasiswa PGSD FKIP Universitas Djuanda; Pengenalan profil dosen dan mahasiswa PGSD FKIP Universitas Djuanda; dan Identifikasi permasalahan spesifik yang sedang dihadapi mitra.

\section{Rapat Koordinasi tim PKM}

Rapat ini diadakan tanggal 10 Desember 2014 pukul 08.00 - 17.00 WIB di Ruang Yudhistira Lantai 2 Gedung Kalbis Institute Jl. Pulomas Selatan Kav.22 Jakarta Timur. Rapat ini untuk membicarakan: Tema pelatihan yang dibutuhkan oleh mitra; Waktu dan tempat pelaksanaan kegiatan PKM; Identifikasi permasalahan spesifik yang sedang dihadapi mitra; Peserta pelatihan; dan Instruktur pelatihan

\section{E. Pembuatan Proposal PKM}

Proposal PKM dengan tema "Mendesain Bahan Ajar Berbasis Multimedia bagi Dosen dan Mahasiswa PGSD - FKIP Universitas Djuanda Bogor" dibuat tanggal 17 Desember 2014 pukul 08.00 - 12.00 WIB oleh tim PKM.

\section{F. Pembuatan Materi Pelatihan PKM}

Dalam rapat Tim PKM pada 24 Desember 2014 pukul 08.00 - 12.00 WIB di ruang dosen Lantai 2 Kampus Institut Teknologi dan Bisnis Kalbis Jl. Pulomas Selatan Kav.22 Jakarta Timur dibicarakan materi yang akan diberikan pada acara PKM bulan Januari 2015 dengan tema " Mendesain Bahan Ajar Berbasis Multimedia bagi Dosen dan Mahasiswa PGSD-FKIP Universitas Djuanda Bogor".

\section{G. Pelaksanaan PKM tanggal 19 dan 26 Januari 2015}

Kegiatan pelatihan untuk dosen dan mahasiswa PGSD FKIP Universitas Djuanda Bogor dilaksanakan tanggal 19 dan 26 Januari 2015, bertempat di ruang Micro Teaching FKIP Universitas Djuanda Bogor. Pelatihan ini merupakan kegiatan PKM gabungan antara dosen prodi Sistem Informasi dengan dosen prodi Ilmu Komunikasi Kalbis Institute. Tim PKM dari Prodi Sistem Informasi yang berjumlah sebanyak 2 (dua) orang dosen dan 2(dua) orang mahasiswa. Sedangkan dari prodi Ilmu Komunikasi berjumlah 2 (dua) orang dosen. Peserta pelatihan berjumlah 17 orang pada hari pertama dan 8 orang pada hari kedua.

Tanggal 19 Januari 2015 pukul 08.00 WIB acara dimulai dengan registrasi peserta pelatihan oleh tim PKM. Acara dilanjutkan dengan pembukaan oleh Wakil Dekan II FKIP UNIDA Bogor Ibu Rusi Rusmiati Aliyyah, M.Pd serta Kepala Laboratorium PSB FKIP UNIDA Bogor Ibu Widyasari. Dalam pembukaan tersebut Ibu Rusi Rusmiati Aliyyah, M.Pd mengucapkan terima kasih atas kesediaan tim PKM untuk bekerjasama dengan UNIDA. Dalam sambutannya Ibu Rusi Rusmiati Aliyyah, M.Pd juga menjelaskan sekilas tentang Universitas Djuanda Bogor. Acara dilanjutkan dengan sambutan dari Dekan Fakultas Ilmu Komputer dan Ilmu Komunikasi dan Kepala Biro P3KM Kalbis Institute Bapak Dr. Hadi Sutopo, S.Kom, MMSI. Beliau menyampaikan bahwa kegiatan pengabdian kepada masyarakat merupakan salah satu wujud Tri Dharma Perguruan Tinggi. Bapak Hadi Sutopo juga mengucapkan terima kasih atas kepercayaan UNIDA kepada dosen Kalbis Insitute untuk memberikan pelatihan kepada 
para dosen dan mahasiswanya. Beliau juga berharap semoga kegiatan pengabdian kepada masyarakat ini memberikan manfaat bagi para dosen dan mahasiswa FKIP UNIDA khususnya dalam membekali dan mempersiapkan para dosen ataupun mahasiswa agar kedepannya bisa mendesain bahan ajar berbasis multimedia. Beliau juga berharap semoga pelatihan ini tidak hanya sekali saja dan bisa berkesinambungan karena materi pelatihan yang diberikan sangat dibutuhkan dalam meningkatkan pengetahuan untuk bisa mendukung pengembangan para dosen dan mahasiswa untuk bisa mengembangkan bahan ajar yang lebih interaktif.

Pukul 09.30 WIB acara dilanjutkan dengan pelatihan mengenai Komunikasi Multimedia. Pada bagian ini materi yang diberikan antara lain: Perangkat Multimedia, Perkembangan Multimedia dan Pengaruh Multimedia. Instruktur pada materi ini adalah Ibu Satya Candrasari, S.Sos, M.Ikom. Pukul 10.30 - 12.00 WIB materi Komunikasi Multimedia dilanjutkan oleh Bapak Salman, M.Si dengan materi antara lain: Manfaat Multimedia, Karir Multimedia, dan Aplikasi Multimedia.

Setelah istirahat pukul $13.30-14.30$ WIB acara dilanjutkan dengan pelatihan Mendesain Bahan Ajar Berbasis Multimedia dengan materi Pengenalan Flash yaitu Memahami autoring tools Flash, Memahami pembuatan gambar dalam dokumen Flash dan Membuat animasi gambar frame-by-frame. Instruktur pada materi ini adalah Ibu Ridha Sefina Samosir, S.Si, M.Kom. Pukul 14.30 - 15.30 WIB dilanjutkan oleh instruktur Ibu Mira Ziveria, S.Si, MT dengan materi Animasi Dasar, antara lain: Membuat animasi gambar frame-by-frame, Membuat animasi tweening, dan Membuat animasi shape tweening. Pukul 15.30 - 16.45 WIB dilanjutkan oleh Bapak Dr. Hadi Sutopo, S.Kom, MMSI dengan materi Animasi Teks dan Image yaitu Membuat animasi teks, Membuat animasi dengan transformasi, serta Membuat animasi dengan mask. Pukul 16.45 - 17.00 WIB pelatihan hari pertama ditutup oleh Ibu Widyasari selaku perwakilan dari Universitas Djuanda Bogor.

Tanggal 26 Januari 2015 pukul 08.00 WIB pelatihan hari kedua dimulai dengan meregistrasi peserta pelatihan oleh tim PKM. Acara dilanjutkan dengan pembukaan oleh Ibu Widiasari Kepala Laboratorium PSB PGSD FKIP Universitas Djuanda Bogor. Pukul 09.15 WIB acara dilanjutkan dengan pelatihan mengenai Mendesain Bahan Ajar Berbasis Multimedia, yaitu materi tentang pembuatan Button, antara lain: Membuat button, Membuat button dengan image, dan Membuat button dengan animasi.
Instruktur pada materi ini adalah Ibu Ridha Sefina Samosir, S.Si, M.Kom. Pukul 10.45 - 12.00 WIB materi dilanjutkan oleh Ibu Mira Ziveria, S.Si, MT dengan materi Interaktif, antara lain: Membuat action pada frame, Membuat interaktif dengan button, dan Mengendalikan movie clip dengan button.

Setelah istirahat pukul $13.30-15.00$ WIB acara dilanjutkan dengan pelatihan Mendesain Bahan Ajar Berbasis Multimedia dengan instruktur Bapak Dr. Hadi Sutopo, S.Kom, MMSI dan materinya mengenai Presentasi yaitu Merancang presentasi, Membuat presentasi berdasarkan frame, Menggunakan symbol, Membuat animasi motion tweening, Membuat animasi dengan mask, Membuat interaktif dengan button, serta Menggunakan audio.

Pukul 15.00 - 16.45 WIB acara dilanjutkan dengan Latihan dan Presentasi peserta pelatihan. Disini peserta pelatihan dibagi menjadi beberapa kelompok dan setiap kelompok harus mempresentasikan bahan ajar yang didesain menggunakan multimedia. Pukul 16.45 - 17.00 WIB pelatihan hari kedua ini ditutup oleh Ibu Widyasari selaku perwakilan dari Universitas Djuanda Bogor.

Pelaksanaan kegiatan pelatihan yang dilaksanakan tgl 19 dan 26 Januari 2015 di Ruang Micro Teaching ini ditunjukkan dengan Surat Keterangan No.86/01/SKET-FKIP/I/2015 yang ditandatangani oleh Dekan FKIP UNIDA Bogor Ibu Hj. R. Siti Pupu Fauziah, M.Pd.I.

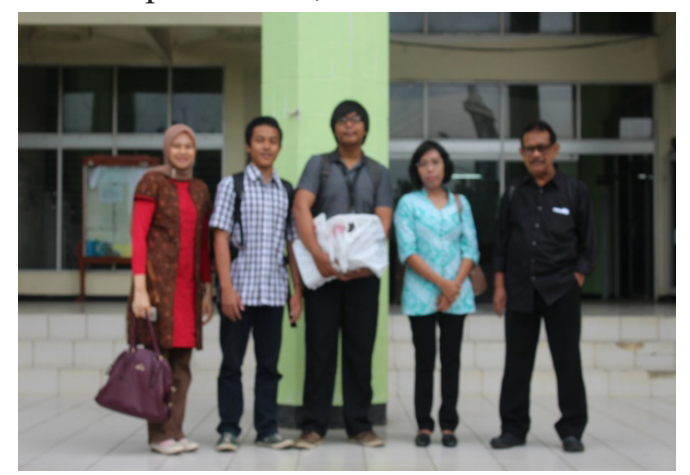

Gambar 3. Kedatangan tim PKM di FKIP Universitas Djuanda

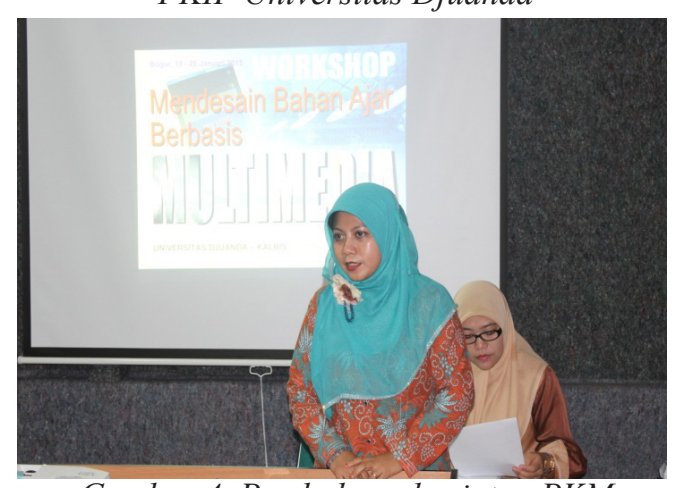

Gambar 4. Pembukaan kegiatan PKM oleh Wakil Dekan II FKIP UNIDA Ibu Rusi Rusmiati Aliyyah, M.Pd. 


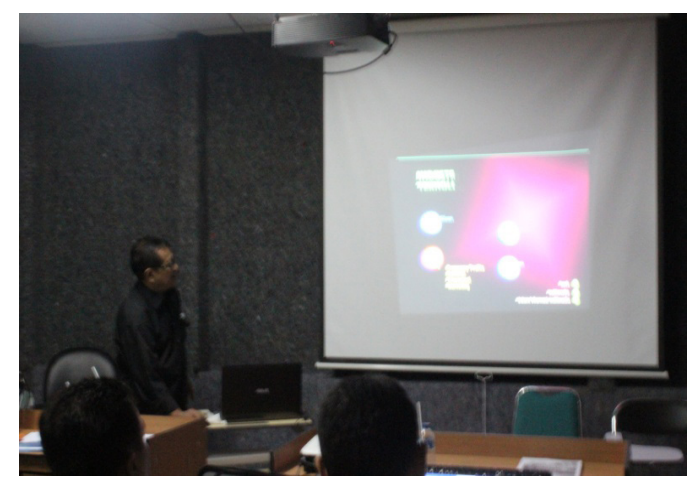

Gambar 5. Sambutan Dekan FIKIK dan Kepala Biro P3KM Kalbis Institute Bapak Dr. Hadi Sutopo, S.Kom, MMSI.

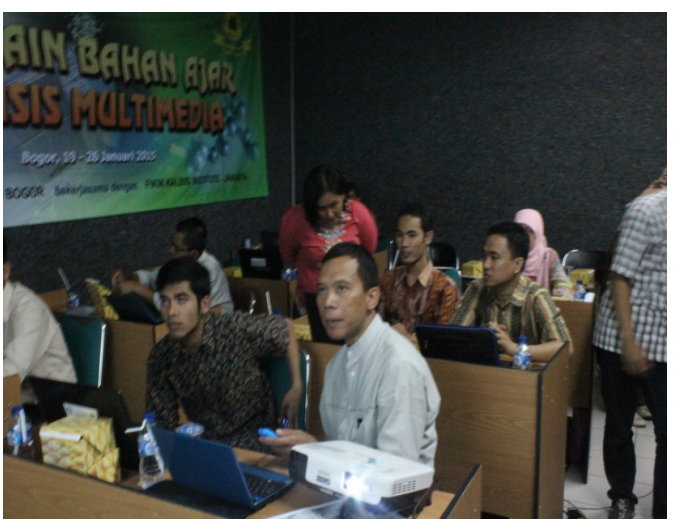

Gambar 6. Peserta pelatihan PKM

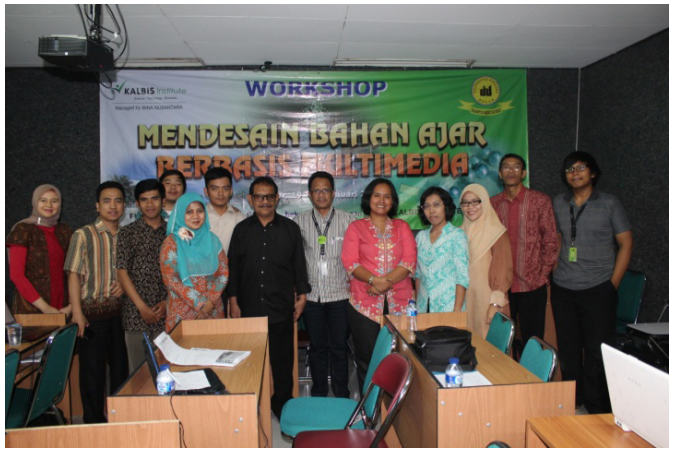

Gambar 7. Instruktur dan peserta pelatihan pada penutupan pelatihan tanggal 19 Januari 2015

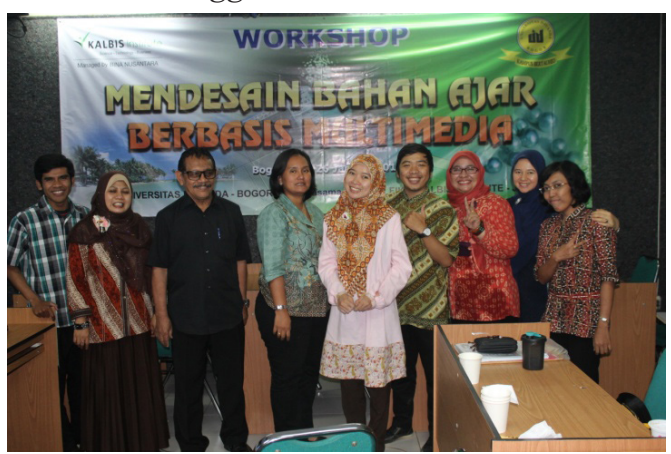

Gambar 8. Instruktur dan peserta pelatihan pada penutupan pelatihan tanggal 26 Januari 2015

\section{H. Evaluasi dan Laporan Kegiatan PKM}

Evaluasi kegiatan dan pembuatan laporan akhir atas pelatihan yang telah diberikan kepada dosen dan mahasiswa PGSD - FKIP Universitas Djuanda Bogor yang dilakukan pada tanggal 30 Januari 2015 pukul $13.00-17.00 \mathrm{WIB}$.

\section{SIMPULAN}

Kegiatan PKM yang telah dilaksanakan pada tanggal 19 dan 26 Januari 2015 dapat disimpulkan bahwa kegiatan ini memberikan pengetahuan baru bagi dosen dan mahasiswa PGSD FKIP Universitas Djuanda mengenai keterampilan mendesain bahan ajar secara menarik dan interaktif berbasis multimedia menggunakan Adobe Flash. Para peserta terlihat sangat antusias mengikutinya karena materi pelatihan sesuai dengan kebutuhan peserta. Keingintahuan peserta sangat besar, hal ini menjadikan materi pelatihan dapat tersampaikan secara keseluruhan.

\section{DAFTAR RUJUKAN}

[1] Hofstetter (2001). Multimedia Interaktif. Yudistira. Jakarta.

[2] Setyosari, P dan Sihkabuden (2005). Media Pembelajaran. Elang Mas. Malang.

[3] Sadiman, A. (2008). Media Pendidikan, Pengertian, Pengembangan, dan Pemanfaatannya. PT. Rajagrafindo Persada. Jakarta.

[4] Sutopo, A. H. (2008). Pengenalan Adobe Flash. PT Elex Media Komputindo. Jakarta. 